\title{
Knowledge Level of Working and Student Nurses on Cervical Cancer and Human Papilloma Virus Vaccines
}

\author{
Aysel Topan ${ }^{1 *}$, Ozlem Ozturk², Hulya Eroglu³, Ozgur Bahadir ${ }^{3}$, Muge Harma ${ }^{4}$, \\ Mehmet Ibrahim Harma ${ }^{4}$
}

\begin{abstract}
Purpose: To determine knowledge levels of working and student nurses about cervical cancer and prophylactic cancer vaccines. Materials and Methods: This study was performed on 259 nursing students in the Department of Nursing and 137 nurses working in Health Research and Practice Center, approved to participate in the study between April-June 2012. The study was performed universally without selecting a sample. A questionnaire that was prepared for evaluating participants' knowledge and attitudes about human papilloma virus (HPV) vaccine was distributed to the nurses and data obtained from the forms were transferred to SPSS 15.00 program and statistically analyzed. Results: It was found that 54.8\% of the student nurses were between 21-24 years old and $13.1 \%$ of working students were between $25-28$ years old. When student nurses and working nurses were compared in terms of their knowledge about the causes of cervical cancer, their ideas about prevention from cervical cancer with HPV vaccine, their ideas about possible risks of HPV vaccine and conservation ratios of HPV vaccine, it was observed that there were no statistically significant differences $(p>0.05)$. When student nurses and working nurses were compared in terms of the information-source about HPV, ways of HPV contamination, awareness about people who are susceptible to HPV contamination and age of HPV vaccination, it was determined that there was a statistically significant difference $(p<0.05)$. Conclusions: It was found that all nurses had some knowledge about cervical cancer and HPV vaccine, but this was not sufficient. Therefore; it is recommended to use verbal, written and visual communication tools intensively in order to have topics on cervical cancer, early diagnosis and prevention in bachelor and master programs for nurses, to inform society about cervical cancer and HPV vaccine for public health and to teach precautions for its prevention.
\end{abstract}

Keywords: Cervical cancer - vaccine - HPV - Turkish nurses - students - knowledge

Asian Pac J Cancer Prev, 16 (6), 2515-2519

\section{Introduction}

Cervical cancer is a preventable and significant public health problem all over the world, especially in developing countries (Kose et al., 2014). Cervical cancer is the most frequent gynecological cancer in women and it is the second cancer frequently seen among women. Cervical cancer constitutes $15 \%$ of all malignancies among women in developing countries and its lifetime risk is around $3 \%$. It is estimated by World Health Organization that more than 2 million women in the world are suffering from cervical cancer (Sahiner and Sener, 2013). The most significant risk factor in cervical cancer is HPV (Human Papilloma Virus) virus infection (Kose et al., 2014). HPV is a sexually transmitted disease. Moreover, disease can progress commonly and rapidly in case of pregnancy, AIDS and cortisone therapy in which immune system of the individual is not sufficient (Ozsaran et al., 2011). 40 out of 118 HPV types cause genital infection. There are
14 types of high risk HPV available. Studies performed in recent years showed that the most significant method among cervical cancer prevention methods is HPV vaccine. In June 2006, HPV vaccine $(6,11,16,18$ types) was approved by FDA as 3 doses in 9-26 age group. Prophylactic HPV vaccines prevent individuals, who were not infected by HPV, from HPV infection and its risks (cervix, vagina, vulva, penile cancer and genital warts). Although there is a view that it should be applied before the onset of sexual activity theoretically, it was reported that it has a protection during sexually active period (Kurt et al., 2013).

Cervical cancer is ranked tenth among all women cancers in our country and its incidence is 4.76 in 100.000. Based on these data, incidence of cervical cancer has increased in our country and early diagnostic studies are below many countries in the world that have national screening programs. It is expected that healthcare professionals should be the individuals who have the

${ }^{1}$ Department of Nursing, School of Health, ${ }^{3}$ Health Application and Research Center, ${ }^{4}$ Department of Obstetrics and Gynecology, Faculty of Medicine, Bulent Ecevit University, Zonguldak, ${ }^{2}$ Department of Nursing, School of Health, Karabuk University, Karabuk, Turkey*For correspondence: ayskose@hotmail.com 
highest knowledge level and who are most conscious about cervical cancer in a society. As an important member of a health team, nurses should take the responsibility of health protection and promotion for the individuals who they provide healthcare besides their responsibilities for their own health. Therefore, nurses should have sufficient knowledge about cervical cancer and prevention methods regardless of their areas of work (Guvenc et al., 2012).

\section{Materials and Methods}

\section{Type of the study}

This is a descriptive comparative study.

\section{Universe of the study and sample selection}

The study was performed on students in Nursing Department of Zonguldak Health School and the nurses working in Health Practice and Research Center and who approved to participate in the study between AprilJune 2012. It was performed on whole universe without selecting a sample. Study was performed with 259 nursing students and 137 working nurses.

\section{Data collection tools}

A questionnaire form consisting of a total of 23 open ended, multiple choice questions which were prepared by obtaining an expert advice was used as the data collection tool. Questionnaire that was prepared to evaluate knowledge and attitudes about cervical cancer and HPV vaccine, was given to the students and working nurses by the researchers and they were asked to fill the form after being informed about the questions.

\section{Data analysis}

Data obtained from the study were transferred to SPSS 15.00 program and statistical analyses were performed. Chi-Square test was used in inter-group comparisons. The results of the analyses were assessed within $95 \%$ confidence interval.

\section{Ethical aspect of the study}

All necessary institutional permits and ethics commitee approval were taken in order to perform the study.

\section{Results}

When sociodemographic characteristics of the students and working nurses participating in the study were examined, it was found that $83 \%$ of student nurses were women and $83.8 \%$ were between $21-24$ years old; $84.7 \%$ of working nurses were women and $38 \%$ of them were between 25-28 years old.

$60.2 \%$ of student nurses and $56.2 \%$ of working nurses have given "yes" response and declared that they knew causes of cervical cancer; and no statistically significant difference was found between groups in terms of their status of awareness ( $p>0.05) .84 .6 \%$ of student nurses and $82.5 \%$ of working nurses reported that HPV virus may cause cervical cancer and it was observed that there was not a statistically significant difference between groups ( $>>0.05$ ). $3.1 \%$ of student nurses and $2.2 \%$ of working nurses declared that there was cervical cancer in their families and it was detected that there was not a statistically significant difference between groups for family history $(\mathrm{p}>0.05)$.

$23.9 \%$ of the students and $24.1 \%$ of the nurses have declared that they gave information and advice to the people around themselves about cervical cancer and no statistically significant difference was found between groups in terms of providing information $(\mathrm{p}>0.05) .87 .3 \%$ of student nurses and $86.1 \%$ of working nurses have reported that cervical cancer can be diagnosed at early stages and it was determined that there was no statistically significant difference between groups in terms of their ideas about early diagnosis ( $\mathrm{p}>0.05)$.

$88.4 \%$ of student nurses and $85.4 \%$ of working nurses have reported that cervical cancer can be treated if diagnosed earlier. It was found that there was no statistically significant difference between both groups when their ideas about treatability of cervical cancer when diagnosed earlier were compared $(\mathrm{p}>0.05)$. $89.6 \%$ of student nurses and $87.6 \%$ of working nurses have declared that protection from cervical cancer is possible and there was not a significant difference between groups in terms of protection from cervical cancer $(\mathrm{p}>0.05)$.

$21.2 \%$ of student nurses and $16.1 \%$ of working nurses declared that HPV virus always shows signs and there was no significant difference between both groups $(\mathrm{p}>0.05)$. $77.6 \%$ of student nurses and $78.1 \%$ of working nurses have indicated that cervical cancer can be prevented by HPV vaccination and $1.5 \%$ of both student and working nurses said that they underwent HPV vaccination. When their ideas about protection by HPV vaccine and their status of HPV vaccination were compared, it was determined that there was not a statistically significant difference between student and working nurses $(\mathrm{p}>0.05)$.

$59.1 \%$ of student nurses and $52.6 \%$ of working nurses have indicated that they will have HPV vaccination and there was no statistically significant difference between groups in terms of their ideas about vaccination ( $p>0.05)$. $5.8 \%$ of both student and working nurses have indicated that there were people who have vaccination in their families and surroundings; and $77.2 \%$ of student nurses and $73 \%$ of working nurses told that they will approve vaccination for their families/surroundings; and there were no significant difference between both groups for these parameters $(p>0.05) .1 .9 \%$ of student nurses and $3.6 \%$ of working nurses have declared that they thought of HPV vaccine as harmful and there was no statistically significant difference between groups $(\mathrm{p}>0.05)$.

When student and working nurses were compared in terms of their ideas about preventiveness of HPV vaccine, it was observed that there was not a significant difference ( $p>0.05$ ) (Figure 1). $96.1 \%$ of student nurses and $98.5 \%$ of working nurses have declared that HPV vaccine does not get sufficient attention in our country and there was no significant difference between groups ( $p>0.05)$.

Among the sources of information about HPV for the student and working nurses participating in the study, "school" was in the first place in $59.5 \%$ of the students and $48.9 \%$ of the working nurses (Table 1). $29.3 \%$ of student nurses and $25.5 \%$ of working nurses have declared 

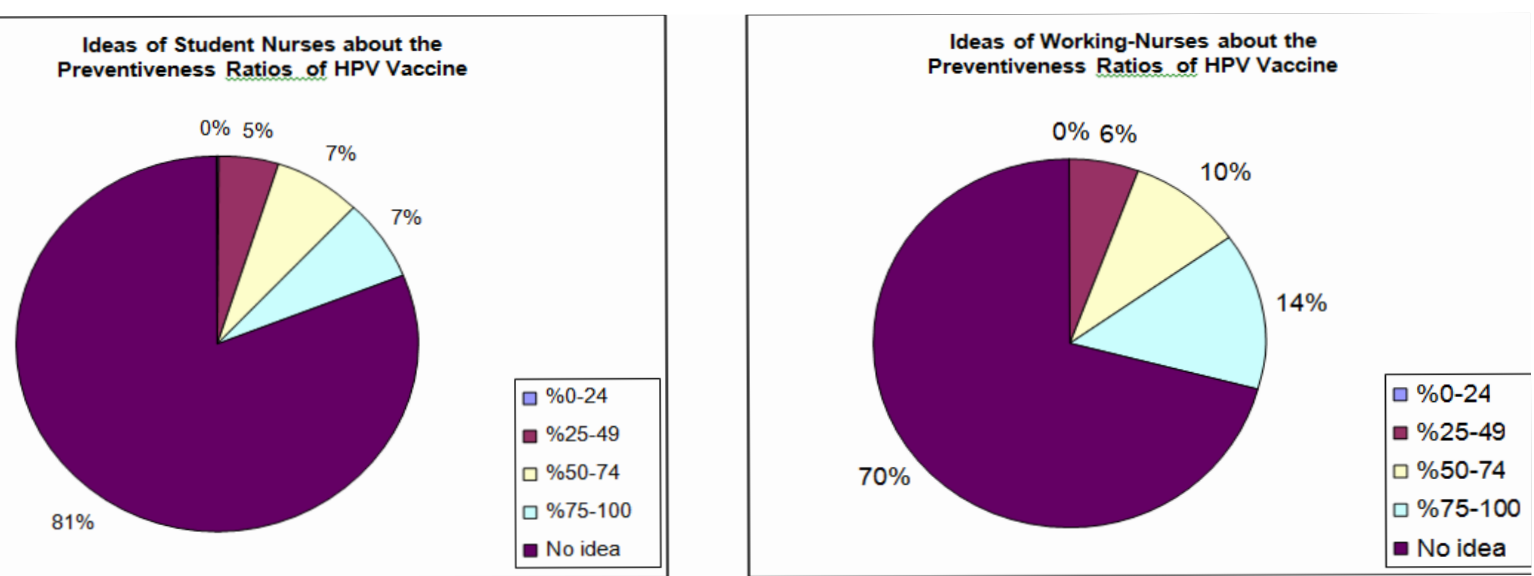

Figure 1. Ideas of Study Groups about Preventiveness Ratios with HPV Vaccines

Table 1. Comparison of Attitudes and Behaviors about Prophylactic Vaccine Cervical Cancer of the Working Group

\begin{tabular}{|c|c|c|c|c|c|c|c|c|c|}
\hline \multirow[t]{2}{*}{ Characteristics } & & \multicolumn{2}{|c|}{$\begin{array}{l}\text { Student Nurse } \\
\quad(\mathrm{n}=259)\end{array}$} & \multicolumn{2}{|c|}{$\begin{array}{l}\text { Working Nurse } \\
\qquad(\mathrm{n}=137)\end{array}$} & \multicolumn{2}{|c|}{$\underset{(n=396)}{\text { Total }}$} & \multicolumn{2}{|c|}{ Test Values } \\
\hline & & $\mathrm{n}$ & $\%$ & $\mathrm{n}$ & $\%$ & $\mathrm{n}$ & $\%$ & $x^{2}$ & $\mathrm{p}$ \\
\hline \multirow{3}{*}{$\begin{array}{l}\text { The source of the information received } \\
\text { about HPV }\end{array}$} & School & 154 & 59.5 & 67 & 48.9 & 221 & 55.8 & 10.27 & 0.04 \\
\hline & I'dont know & 76 & 29.3 & 35 & 25.5 & 111 & 28.1 & & \\
\hline & Others & 29 & 11.2 & 35 & 24.9 & 64 & 16.1 & & \\
\hline \multirow{2}{*}{$\begin{array}{l}\text { Knowledge-level of the routes of } \\
\text { transmission of HPV }\end{array}$} & Yes & 149 & 57.5 & 93 & $67.9 \quad 2$ & 242 & 61.1 & 4.04 & 0.04 \\
\hline & No & 110 & 42.5 & 44 & $32.1 \quad 1$ & 154 & 38.9 & & \\
\hline \multirow{3}{*}{$\begin{array}{l}\text { Knowledge-level of who is } \\
\text { infected with HPV }\end{array}$} & Men infected with HPV & 4 & 1.5 & 5 & 3.6 & 9 & 2.3 & 11.0 & 0.04 \\
\hline & Women infected with HPV & 95 & 36.7 & 29 & 21.2 & 124 & 31.3 & & \\
\hline & Both & 160 & 61.8 & 103 & 75.2 & 263 & 66.4 & & \\
\hline \multirow{4}{*}{ Age when HPV vaccine was inoculated } & $10-24$ & 32 & 12.4 & 34 & 24.8 & 66 & 16.7 & 21.76 & 0.03 \\
\hline & $25-55$ & 61 & 23.5 & 48 & 35 & 109 & 27.5 & & \\
\hline & I'dont know & 166 & 64.1 & 55 & 40.2 & 221 & 55.8 & & \\
\hline & Total & 259 & 100.0 & 137 & 100.0 & 396 & 100.0 & & \\
\hline
\end{tabular}

that they had no information about HPV. When students and working nurses were compared for the source of information about HPV, it was determined that there was a statistically significant difference between groups $(\mathrm{p}=0.04) .57 .5 \%$ of student nurses and $67.9 \%$ of working nurses have indicated that they were aware about HPV transmission ways. When students and working nurses were compared for this parameter, it was observed that there was a statistically significant difference between groups $(p=0.04) .61 .8 \%$ of student nurses and $75.2 \%$ of working nurses have declared that transmission may occur in both sexes (Table 1). When student and working nurses were compared for their ideas about the individuals to whom HPV is transmitted, statistically significant difference was found between groups $(\mathrm{p}=0.04)$.

While $23.5 \%$ of student nurses and $35 \%$ of working ones have indicated HPV vaccination age as "25-55 years old", $64.1 \%$ of the students and $40.2 \%$ of working students told that they did not know HPV vaccination age (Table 1). When student nurses and working nurses were compared for their ideas about HPV vaccination age, it was determined that there was a significant difference between groups $(\mathrm{p}=0.03)$.

\section{Discussion}

In this study, knowledge level of student and working nurses included in the study about HPV vaccine and results including differences between both groups were included and they were compared with literature.

It was determined that majority of 259 student and 137 working nurses were women, and all of student nurses and $72.3 \%$ of working nurses were between $17-28$ years old. This result of the study showed that age distribution of student and working nurses was not very different. This suggests that age profiles of the nurses working in participating university hospital was within younger population.

$60.2 \%$ of student nurses and $56.2 \%$ of working nurses participating in the study have indicated that they knew the causes of cervical cancer; and $84.6 \%$ of student nurses and $82.5 \%$ of working nurses have declared that HPV might cause cervical cancer. In the study by Guvenc et al (2012) on nursing students, $81.6 \%$ of the students who knew health problems caused by HPV have indicated that HPV causes cervical cancer at the highest rate. In the study by Guducu et al (2012), $76.5 \%$ of medical students, $70.6 \%$ of nursing students and $47.7 \%$ of healthcare professionals have reported that HPV is a risk factor for cervical cancer. In the study by Yildirim et al (2009), 92.9\% of pediatricians have reported that HPV infection is the most significant risk factor for cervical cancer. The awareness ratio of working and student nurses participating in the study about the fact that HPV can cause cervical cancer 
was found to be compliant with other studies. However, it was observed in the study by Guducu et al (2012) that the rates of healthcare professionals were quite low compared to medical and nursing students and this result was not found to be compliant with the results of our study. In the studies performed with the groups other than healthcare professionals in our country, it was reported that awareness rates of participants about HPV infection were quite low (Araz et al., 2010; Ozan et al., 2011; Bulbul et al., 2013; Aslan et al., 2014; Cetin et al., 2014). In the study performed abroad, it was reported that knowledge level about HPV and HPV vaccine is low in general population (Walsh et al., 2008; Wong and Sam, 2010). In our study, the rates of expressing that HPV can cause cervical cancer were high in both student and working nurses; and this can be explained by the conditions that working nurses in the study group were younger and graduated recently and they might have obtained information about HPV during their school life. While HPV is considered as the most significant risk factor (Baseman and Koutsky, 2005; Castellsagué et al., 2006), high rates of knowing that HPV might cause cervical cancer by student and working nurses can be interpreted as a positive and favorable outcome.

$23.9 \%$ of student nurses and $24.1 \%$ of working nurses have declared that they gave information and advice to the individuals around themselves about cervical cancer. These low rates can be interpreted as a negative outcome when their active roles in informing public about diseases are considered.

$77.2 \%$ of student nurses and $73 \%$ of working nurses have indicated that they will approve vaccination for their families/individuals around themselves. In some studies in the literature, participants wanted family members/ individuals around themselves to be vaccinated at higher rates compared to our study (Yildirim et al., 2009; Onsuz et al., 2011), but in the other studies, it was observed that these rates were lower compared to our results

(Ozan et al., 2011; Guducu et al., 2012; Bulbul et al., 2013). While request for vaccination to their daughters was reported to be more than $50 \%$ in Turkish women (Ilter et al., 2010), it was found that our study results are compliant with the literature.

It was determined that $1.5 \%$ of both student and working nurses had HPV vaccination. Similar to the results of our study, it was also observed that HPV vaccination rates were low in the studies performed in our country (Ilter et al., 2010; Ozsaran et al., 2011; Guducu et al., 2012; Cetin et al., 2014). The reason of lower HPV vaccination rates can be explained by the fact that quadrivalent vaccine was approved in 2007 and bivalent vaccine was approved in 2008 by Health of Ministry (Arvas, 2007; Samer, 2009) and it has been used for five years. Besides, prevalence of HPV was reported to be low as $2-4 \%$ in our country (Arvas, 2007; Inal et al., 2007); therefore, this can be interpreted by lack of attention to HPV and cervical cancer. However; in another literature, it was reported that cervical cancer was ranked ninth among common cancers seen in women in our country (Dursun et al., 2009). Due to increase in extramarital sexual intercourse and number of partners and the reduction in age of the onset of unprotected sexual intercourse in our country (Ozdemir et al., 2003; Aydin, 2013), it is suggested that the increase in the prevalence of HPV is inevitable. Therefore; planning studies on putting HPV vaccine into vaccination calendar also in our country as in the countries such as USA, Canada and Germany makes us think that vaccination rates will increase (Aksayan et al., 2002; Samer, 2009).

In the sources of information about HPV for student and working nurses participating in the study, "school" was in the first place in $59.5 \%$ of the students and $48.9 \%$ of working students. In the study by Cetin et al (2014), the source of information about HPV for the adolescents in the study was reported as written and visual media in the first place. While this finding was not found to be compliant with the results of our study, the fact that individuals who are not healthcare professionals learn a medical concept such as HPV from written and visual media outside of school may be explained as an expected outcome. Similar to our results, it was reported that "school" was in the first place for the source of information about HPV for participants in the other studies performed (Ozsaran et al., 2011; Guvenc et al., 2012).

It was determined that $57.5 \%$ of student nurses and $67.9 \%$ of working students knew HPV transmission ways. HPV is the most common sexually transmitted disease (Baseman and Koutsky, 2005). In the studies performed with healthcare professionals or medical students in our country, rates of knowing that HPV infection is a sexually transmitted disease were found to be higher than the rates in our study (Yildirim et al., 2009; Guducu et al., 2012). Low rates of knowing HPV transmission ways among student and working nurses in our study can be explained by the lack of information about HPV among participants.

While $12.4 \%$ of student nurses and $24.8 \%$ of working ones have declared HPV vaccination age as " $10-24$ years old", $64.1 \%$ of the students and $40.2 \%$ of the working nurses indicated that they did not know HPV vaccination age. In the studies on healthcare professionals, it was observed that rates of lack of knowledge about HPV vaccination age were lower than our study (Yildirim et al., 2009; Onsuz et al., 2011). Low rates of knowing HPV vaccination age suggest that they do not have adequate information about HPV vaccination and vaccination age. When the roles of nurses, who are healthcare professionals, in increasing vaccination rates in the society is considered, it is obvious that this is not a pleasing outcome.

In conclusion, in the light of the results of this study, it was found that student and working nurses have some information about cervical cancer and HPV vaccine but this is not adequate. Therefore; it is recommended to use verbal, written and visual communication tools intensively in order to include topics on cervical cancer, early diagnosis and prevention in bachelor and master programs for nurses, to inform society about cervical cancer and HPV vaccine for public health and to teach precautions for its prevention. Since HPV vaccine should be applied during childhood and adolescence period, especially children nurses should have knowledge about this subject and inform families of the children at this period about this subject (Aksayan et al., 2002) . 


\section{References}

Aksayan S, Bahar Z, Bayik A, et al (2002). Research, Principles, Process and Methods in Nursing, Istanbul, Hemsirelikte Arastirma ve Gelistirme Dernegi, Adak Ofset 19, 290-6 (in Turkish).

Araz NC, Atalay HS, Parlar S (2010). Knowledge \& opinions toward of the higher school of health students about childhood immunization and new vaccine. Turkiye Klinikleri Pediatri Dergisi, 19, 290-6 (in Turkish).

Aslan E, Bektas H, Basgol S, et al (2014). Knowledge and behaviour of university students related to sexual health. Sted Dergisi, 23, 174-82 (in Turkish).

Aydin D (2013). Adolescence pregnancy and adolescence motherhood. Anadolu Hemsirelik ve Saglik Bilimleri Dergisi, 16, 250-4 (in Turkish).

Baseman J, Koutsky L (2005). The epidemiology of human papillomavirus infections. J Clin Virol, 32, 16-24.

Bulbul S, Yalcin S, Araz NC, et al (2013). Thoughts of mothers with children 0-15 years of age about cervical cancer and hpv vaccination in Anatolia. . Turkiye Cocuk Hastaliklari Dergisi, 2, 73-8 (in Turkish).

Castellsagué X, Diaz M, de Sanjosé S, et al (2006). Worldwide human papillomavirus etiology of cervical adenocarcinoma and its cofactors:implications for screening and prevention. J Natl Cancer Inst, 98, 303-15.

Cetin O, Verit FF, Keskin S, et al (2014). Knowledge levels of adolescent girls about human papilloma virus and its vaccine. Turk Pediatri Arsivi, 49, 142-7 (in Turkish).

Dursun P, Senger SS, Arslan H, et al (2009). Human papillomavirus (HPV) prevalence and types among Turkish women at a gynecology outpatient unit. BMC Infectious Diseases, 9, 191-5.

Guducu N, Gonenc G, Isci H, et al (2012). Awareness of human papilloma virus, cervical cancer and HPV vaccine in healtcare workers and students of medical and nursing schools. J Clin Exp Invest, 3, 318-25.

Guvenc G, Akyuz A, Seven M (2012). Determination of the knowledge and attitudes of nursing students about human papilloma virus infection and its vaccines. Gulhane Tip Dergisi, 54, 104-10 (in Turkish).

Ilter E, Celik A, Haliloglu B, et al (2010). Women's knowledge of Pap smear test and human papillomavirus: acceptance of HPV vaccination to themselves and their daughters in an Islamic society. Int J Gynecol Cancer, 20, 1058-62.

Inal MM, Kose S, Yildirim Y, et al (2007). The relationship between human papillomavirus infection and cervical intraepithelial neoplasia in Turkish women. Int J Gynecol Cancer, 17, 1266-70.

Kose D, Erkorkmaz U, Cinar N, et al (2014). Mothers' knowledge and attitudes about HPV vaccination to prevent cervical cancers. Asian Pac J Cancer Prev, 15, 7263-6.

Kurt AS, Canbulat N, Savaser S (2013). Cervical cancer and risk factors of featured with adolescent sexuality. Bakirkoy Tip Dergisi, 9, 59-63.

Ozan H, Demir BC, Atik Y, et al (2011). Determination of Knowledge Level of Patients Regarding HPV and HPV Vaccine in Outpatient Clinic of Obstetrics and Gynecology Department. Uludag Universitesi Tip Fakultesi Dergisi, 3 , 145-8 (in Turkish).

Onsuz MF, Topuzoglu A, Bilgi Z, et al (2011). The evaluation of the knowledge levels and attitudes of medical students who have accomplished obstetric and gynaecological diseases internship in a medical school about human papilloma virus vaccine. . TAF Preventive Medicine Bulletin, 5, 557-64 (in Turkish).

Ozdemir L, Ayvaz A, Poyraz O (2003). The level of knowledge of students in Cumhuriyet university about the sexually transmitted diseases. Cumhuriyet Universitesi Tip Fakultesi Dergisi, 25, 10-4 (in Turkish).

Ozsaran Z, Demirci S, Aras AB (2011). A survey: assessment of knowledge level of HPV vaccine among students of medicine faculty. Turk Jinekolojik Onkoloji Dergisi, 2, 40-4 (in Turkish).

Samer A (2009). Human papilloma virus vaccines. ANKEM Dergisi, 23, 96-101. (in Turkish)

Sahiner F, Sener K (2013). Human papillomavirus infections, risk factors, and preventive measures. TAF Preventive Medicine Bulletin, 6, 715-22 (in Turkish).

Walsh CD, Gera A, Shah M, et al (2008). Public knowledge and attitudes towards human papillomavirus (HPV) vaccination. BMC Public Health, 8, 368.

Wong LP, Sam IC (2010). Ethnically diverse female university students' knowledge and attitudes toward human papillomavirus (HPV), HPV vaccination and cervical cancer. Eur J Obsts Gynecol Reproductive Biol, 148, 90-5.

Yildirim M, Duzovali O, Kanik A, et al (2009). Human papillomavirus infections, risk factors, and preventive measures. Cocuk Enfeksiyon Dergisi, 3, 62-8 (in Turkish). 